\title{
Asymmetric Synthesis of Primary Amines via the Spiroborate- Catalyzed Borane Reduction of Oxime Ethers
}

\author{
Xiaogen Huang, Margarita Ortiz-Marciales ${ }^{\star}$, Kun Huang, Viatcheslav Stepanenko, Francisco \\ G. Merced, Angel M. Ayala, Wildeliz Correa, and Melvin De Jesús \\ Department of Chemistry, University of Puerto Rico-Humacao, CUH Station, Humacao, Puerto Rico \\ 00791, USA
}

\section{Abstract<smiles>C/C(=N\O)c1ccccc1</smiles>

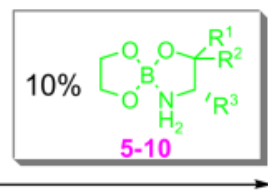 \\ $\mathrm{BH}_{3}$ THF<smiles>CC(N)c1ccccc1</smiles> \\ ( up to $99 \%$ ee)}

The enantioselective borane reduction of $O$-benzyloxime ethers to primary amines was studied under catalytic conditions using the spiroborate esters 5-10 derived from non-racemic 1,2-amino alcohols and ethylene glycol. Effective catalytic conditions were achieved using only $10 \%$ of catalyst 5 derived from diphenylvalinol in dioxane at $0{ }^{\circ} \mathrm{C}$ resulting in complete conversion to the corresponding primary amine in up to $99 \%$ ee.

The asymmetric reduction of oxime ethers with non-racemic chiral reducing agents represents an important synthetic route to enantiopure primary amines. ${ }^{1-5}$ Over the past two decades, oxazaborolidines have been developed as chirality transfer reagents for the reduction of the carbonyl and imine functionality. ${ }^{2}$ The borane-mediated catalytic reduction of ketones using 1,3,2-oxazaborolidines has been extensively investigated. ${ }^{2} \mathrm{~b}$ These efforts have led to the synthesis of highly enantiopure alcohols using less than $10 \mathrm{~mol} \%$ of catalyst. Applying this process to the reduction of the $\mathrm{C}=\mathrm{N}$ provides direct access to non-racemic primary amines which are widely used as key intermediaries in the synthesis of pharmaceuticals, chiral auxiliaries and catalysts. ${ }^{1-4}$ For the borane-mediated reduction of oxime ethers, a stoichiometric amount of the oxazaborolidine is usually required to obtain high enantioselectivities. ${ }^{3,4}$ Fontaine et al. ${ }^{3 \mathrm{k}}$ even employed 2.5 equiv of the diphenylvalinolderived B-H oxazaborolidine to achieve complete reduction with high selectivity. Itsuno and coworkers $^{3 \mathrm{~b}}$ reported the first catalytic borane-based reduction of acetophenone $O$-benzyl oxime. With $10 \mathrm{~mol} \%$ of the $(S)$-diphenylvalinol oxazaborolidine, generated in situ, $52 \%$ ee was observed in the product (S)-1-phenylethanamine. This selectivity is much lower than the $93 \%$ ee obtained for this substrate employing 1 equiv of the catalyst.

In addition to their high cost air- and moisture sensitivity, $B$-H oxazaborolidines often contain impurities which diminish their effectiveness. ${ }^{2 \mathrm{c}-\mathrm{e}}$ This has led to the development of alternative catalytic systems for the reduction of oximes, but with only modest success. ${ }^{5}$ In the present study, a truly catalytic and highly enantioselective process for the borane-mediated asymmetric reduction of oxime ethers is reported for the first time. 
Recently, we prepared stable enantiopure spiroborate esters5-10 derived from 1,2-amino alcohols, as new catalysts for the asymmetric reduction of ketones (Fig. 1). ${ }^{6}$ These spiroborates proved to be highly reactive and enantioselective catalysts for this process. Coupled with their operational convenience, we felt that they may provide effective catalysts for reduction of oxime ethers thereby providing a new, highly useful entry to non-racemic amines (Scheme 1). 7

Initially, we examined the reduction of $(E)$-benzyl oxime ether $1 \mathrm{a}(\mathrm{R}=\mathrm{Bn})$ in toluene employing $50 \mathrm{~mol} \%$ of spiroborate ester 5 and 2 equiv of $\mathrm{BH}_{3} \cdot \mathrm{DMS}$ at $50{ }^{\circ} \mathrm{C}$ for $12 \mathrm{~h}$ followed by $3 \mathrm{~h}$ at $110^{\circ} \mathrm{C}$. The amine product $2 \mathrm{a}$ was isolated as its carbamate 4 in $75 \%$ yield and $93 \%$ ee. Seeking milder conditions, we discovered that the reduction could be conducted at $25^{\circ} \mathrm{C}$ in THF solvent and these conditions were used with varying amounts and sources of borane and $\mathbf{5}$ to determine optimal conditions for the reduction. These results are presented in Table 1.

The complete conversion of $\mathbf{1 a}$ to $\mathbf{3}$ under these conditions was achieved by increasing the amount of $\mathrm{BH}_{3}$.DMS to 4 equiv (Table 1, entries 1-3) and using $50 \%$ of spiroborate 5. The reduction of 1a occurred faster and with complete conversion to primary amine $\mathbf{3}$. Decreasing 5 to $25 \%$ and using 6 equiv of $\mathrm{BH}_{3} \cdot \mathrm{DMS}$, the conversion was partial (85\%, entry 5 ). Hence, we decided to use $\mathrm{BH}_{3}$.THF stabilized by $N$-isopropyl $N$-methyl tert-butylamine, which has been demonstrated to be more stable and selective in carbonyl reductions. ${ }^{8}$ Indeed, with $20 \%$ catalyst and using 2.4 equiv $\mathrm{BH}_{3}$. THF a nearly quantitative conversion to 3 was observed $(91 \%$, entry 6). Remarkably, with only $10 \%$ of catalyst and 4 equiv of $\mathrm{BH}_{3}$.THF, the reduction of oxime 1a afforded the primary amine 3 quantitatively with only a slight decrease in $e e(87 \%$, entry 10). It must be mentioned that $\mathrm{BH}_{3}$.DEA was unreactive in this oxime reduction. ${ }^{9}$

A variety of solvents, temperature and borane sources were screened for the reduction of 1a under the previous optimized conditions. ${ }^{10}$ In general, ethereal solvents lead to higher ee's of the isolated product 4 with dioxane giving the best results ( $90 \%$ ee). The reaction temperature was also varied to further optimize the reaction conditions. At $0{ }^{\circ} \mathrm{C}$, the reaction requires longer reaction times for the complete conversion to 3 , but the enantioselectivity is higher (96.5\% ee). The $\mathrm{BH}_{3} \cdot \mathrm{THF}$, stabilized with $\mathrm{NaBH}_{4}$, affords 3 , then treated with $\mathrm{ClC}(\mathrm{O}) \mathrm{OEt}$ produced 4 in $95 \%$ ee at $25^{\circ} \mathrm{C}$ in dioxane. Importantly, this reagent gives $96.5 \%$ ee at $0{ }^{\circ} \mathrm{C}$, the same result as for the amine-stabilized $\mathrm{BH}_{3}$.THF. The $\mathrm{BH}_{3}$. DMS reagent proved to be a less effective borane source for this reduction. Moreover, the selectivity does not change with the addition time of the oxime ether.

The optimized reaction conditions were extended to the other spiroborate esters indicated in Figure 1 . At $0{ }^{\circ} \mathrm{C}$, the reactivity of catalysts $6-9$ was rather low. Therefore, the reaction temperature was changed to $25^{\circ} \mathrm{C}$, except for catalyst 10, whose reactivity was examined at 0 ${ }^{\circ} \mathrm{C}$. Spiroborate ester $\mathbf{5}$ derived from diphenylvalinol shows superior enantioselectivity compared to these other systems. ${ }^{10}$

We further extended these studies to include the methyl and various substituted $O$-benzyl derivatives of acetophenone oxime (4-MeO- $\mathrm{C}_{6} \mathrm{H}_{4} \mathrm{CH}_{2} ; 4-\mathrm{CF}_{3} \mathrm{C}_{6} \mathrm{H}_{4} \mathrm{CH}_{2} ; 2-\mathrm{NO}_{2} \mathrm{C}_{6} \mathrm{H}_{4} \mathrm{CH}_{2}$ ). 10 While these all give excellent selectivities, the $4-\mathrm{CF}_{3}$ substituted benzyl oxime gives 4 in $99 \%$ ee.

Because similar high selectivities were observed with all of the $O$-benzylated acetophenone oximes, the simple $(E)$-benzyl oxime derivatives $\mathbf{1 1}$ of representative aryl alkyl ketones were prepared by standard methods and submitted to the optimized reductive conditions ( 0.1 equiv of 5, dioxane, 25 and $0{ }^{\circ} \mathrm{C}$ ). The product amines were isolated as their $N$-acetyl derivatives 12. In general, the process gives excellent enantioselectivity (83-99\%) at $0{ }^{\circ} \mathrm{C}$. These results are summarized in Table 2. 
In summary, a highly efficient new borane-based catalytic process for the asymmetric synthesis of amines from oxime ethers has been discovered. The new process employs the easily prepared and stable spiroborate ester $\mathbf{5}$ as the chiral transfer agent. Employing simple procedures, this methodology provides a convenient entry to highly versatile and important non-racemic amines. Mechanistic studies and further applications of this new process are underway.

\section{Supplementary Material}

Refer to Web version on PubMed Central for supplementary material.

\section{Acknowledgements}

Financial support by the NIH through their MBRS (GM 08216) and IMBRE (NC P20 PR-016470) Grants is greatly appreciated. The NIH-IMBRE undergraduate support is also gratefully acknowledged.

\section{References}

1. (a) Johansson A. Contemp Org Synth 1995;266:393-406.and ref. cited therein (b) Deloux L, Srebnik M. Chem Rev 1993;93:763-784.

2. (a) Glushkov VA, Tolstikov AG. Russ Chem Rev (Engl Transl) 2004;73:581-608.and ref. cited therein (b) Cho BT. Tetrahedron 2006;62:7621-7643. and ref. cited therein (c) Brown JM, Guy C, Lloyd-Jones GC, Layzell TP. Tetrahedron: Asymmetry 1993;4:2151-2154. (d) Lang A, Noth H, Schmidt M. Chem Ber 1997;130:241-246. (e) Mathre DJ, Thompson AS, Douglas AW, Carroll JD, Corley EG, Grabowski EJJ. J Org Chem 1993;58:2880-2888.

3. (a) Itsuno S, Nakano M, Miyazaki K, Masuda H, Ito K. J Chem Soc Perkin Tran 1 1985:2039-2044. (b) Itsuno S, Sakurai Y, Ito K, Hirao A, Nakahama S. Bull Chem Soc Jpn 1987;60:395-396. (c) Itsuno S, Sakurai Y, Shimizu K, Ito K. J Chem Soc Perkin Trans 1 1990:1859-1863. (d) Bolm C, Felder M. Synlett 1994:655-666. (e) Cho BT, Ryu MH. Bull Korean Chem Soc 1994;15:191-192. (f) Lantos I, Flisak J, Liu L, Matsunoka R, Mendelson W, Stevenson D, Tubman K, Tucker L, Zhang WY, Adams J, Sorenson M, Garigipati R, Erhardt K, Ross S. J Org Chem 1997;62:5385-5391. (g) Demir AS. Pure Appl Chem 1997;69:105-108. (h) Inoue T, Sato D, Komura K, Itsuno S. Tetrahedron Lett 1999;40:5379-5382. (i) Itsuno S, Matsumoto T, Sato D, Inoue T. J Org Chem 2000;65:5879-5881. [PubMed: 10970344] (j) Sailes HE, Watts JP, Whiting A. J Chem Soc Perkin Trans 1;2000:33623374. (k) Fontaine E, Namane C, Meneyrol J, Geslin M, Serva L, Roussey E, Tissandié S, Maftouh M, Roger P. Tetrahedron: Asymmetry 2001;12:2185-2189. (1) Krzeminski MP, Zaidlewicz M. Tetrahedron: Asymmetry 2003;14:1463-1466. (m) Sakito Y, Yoneyoshi Y, Suzukamo G. Tetrahedron Lett 1988;29:223-224.

4. (a) Tillyer RD, Boudreau C, Tschaen D, Dolling U-H, Reider PJ. Tetrahedron Lett 1995;36:43374340. (b) Shimizu M, Kamei M, Fujisawa T. Tetrahedron Lett 1995;36:8607-8610. (c) Shimizu M, Tsukamoto K, Matsutani T, Fujisawa T. Tetrahedron 1998;54:10265-10274. (d) Masui M, Shioiri T. Tetrahedron Lett 1998;39:5195-5198.

5. Chu YB, Shan ZX, Liu DJ, Sun NN. J Org Chem 2006;71:3998-4001. [PubMed: 16674084]

6. (a) Stepanenko V, Ortiz-Marciales M, Correa W, De-Jesús M, Espinosa S, Ortiz L. Tetrahedron: Asymmetry 2006;17:112-115. (b) Ortiz-Marciales, M.; Stepanenko, V.; Correa, W.; De Jesús, M.; Espinosa, S. U S Patent Application. 11/512,599. Aug. 30. 2006

7. Ortiz-Marciales, M.; Huang, X.; Stepanenko, V.; De Jesús, M.; Merced, FG. Provisional U S Patent Application. 60/841,147. Aug. 30. 2006

8. See: Synthetic methods: Reduction, Aldrich Chemfiles 2005;5:4.JosyulaKVBPotyenMGaoPHewittCPatent application pending publication

9. Chung JYL, Cvetovich R, Amato J, McWilliams JC, Reamer R, DiMichele L. J Org Chem 2005;70:3592-3601. [PubMed: 15844996]

10. The details of the results obtained using different solvents, sources of borane, temperature, mode of addition, catalysts and oxime substituents are included in the Supporting Information 


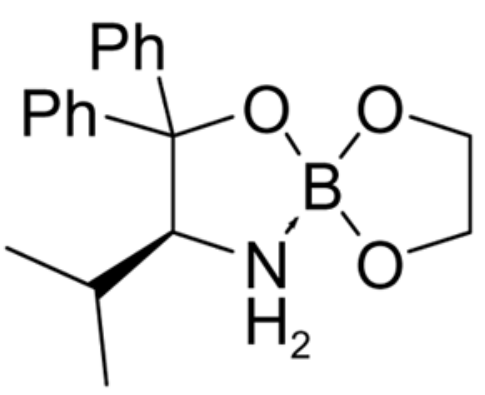

5

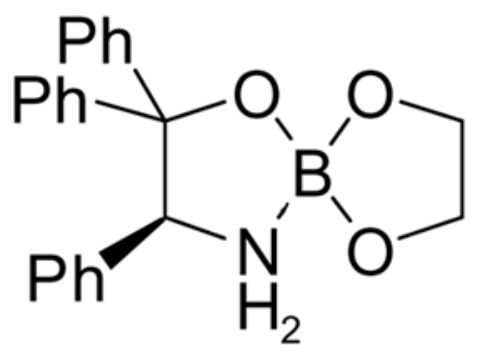

8<smiles>C[C@@H]1N[PH]2(OCCO2)O[C@@H]1P</smiles>

6

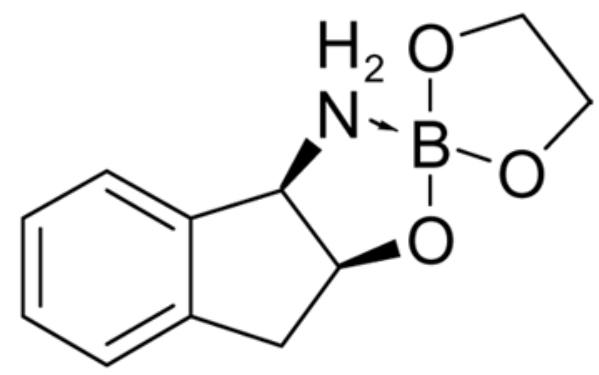

9

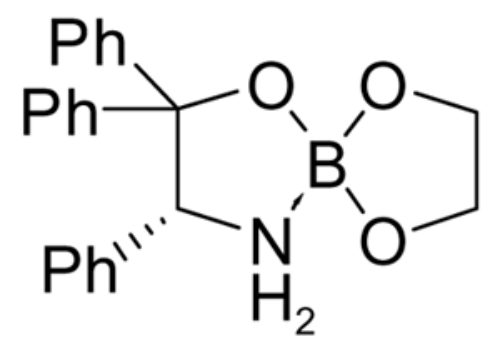

7

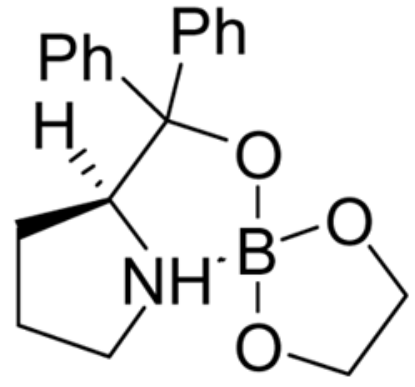

10

Figure 1.

Spiroborate esters derived from non-racemic 1,2-amino alcohols 

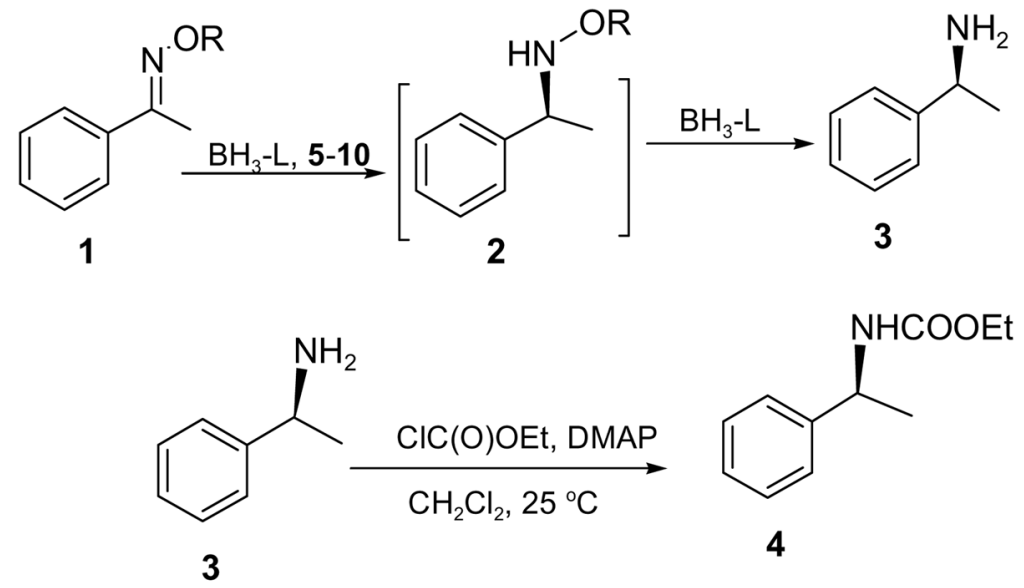

Scheme 1. 


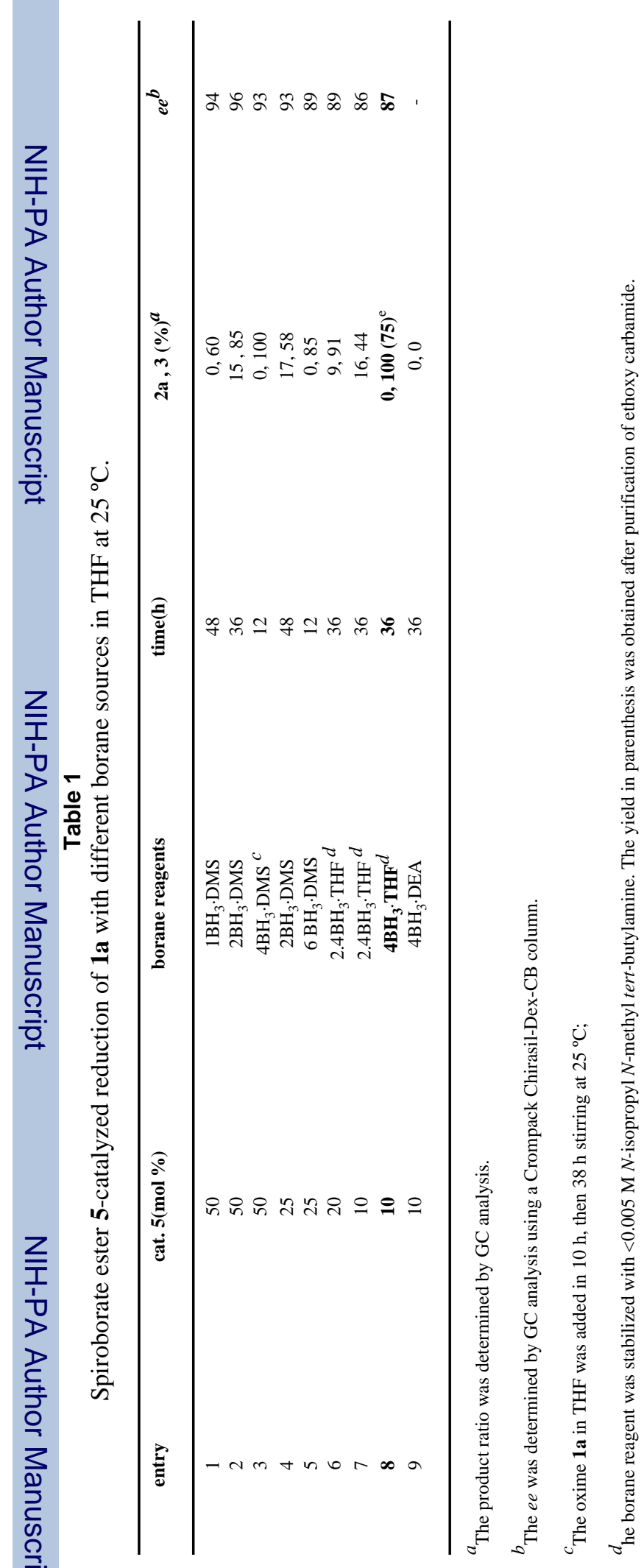

Org Lett. Author manuscript; available in PMC 2008 October 22. 
Table 2

Asymmetric Reduction of Representative Oxime Benzyl Ethers with 0.1 equiv of Catalyst 5

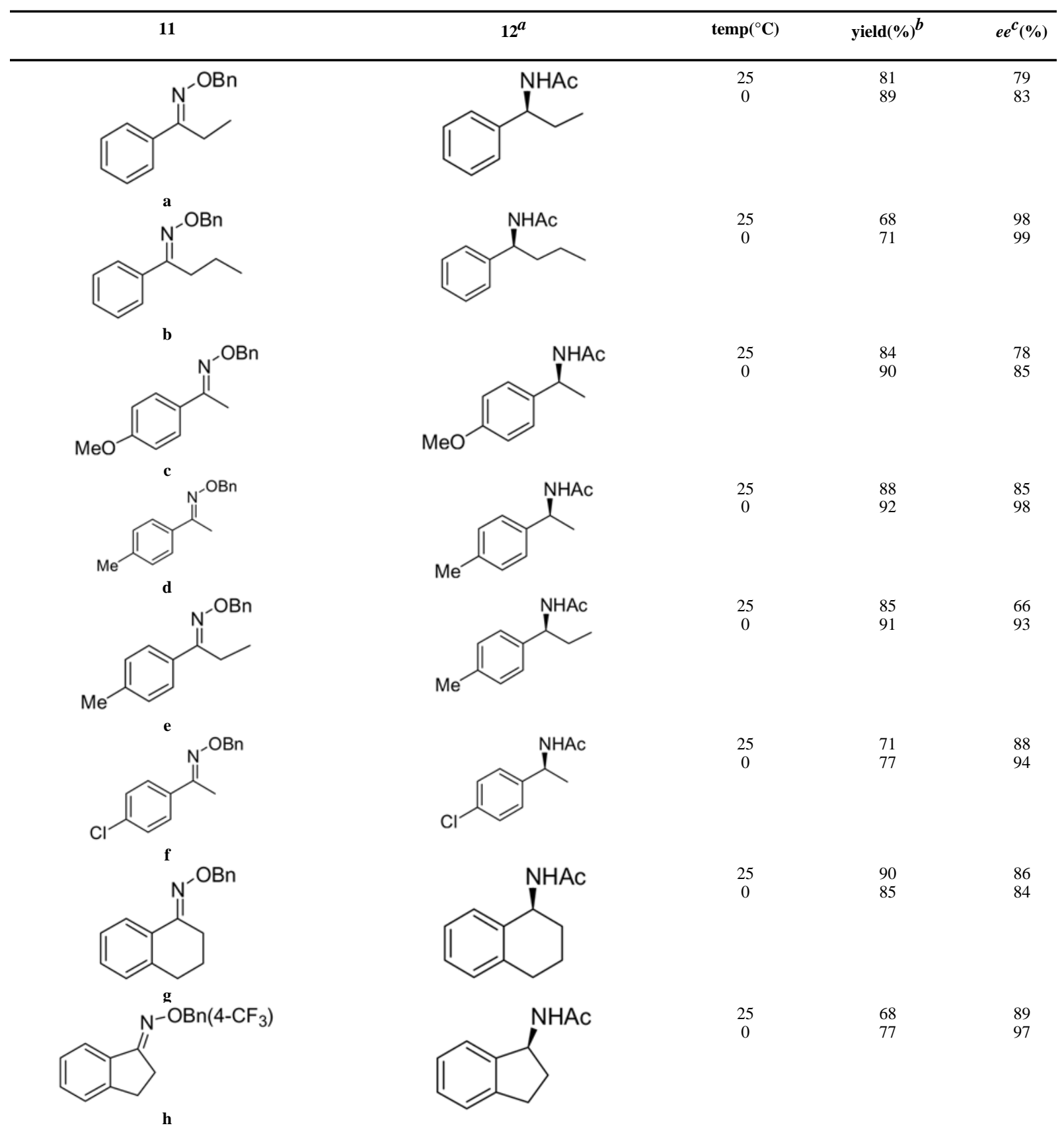

${ }^{a}$ The reactions were carried out using 1 equiv of oxime ether, 0.1 equiv of catalyst 5 and 4 equiv of borane stabilized with $\mathrm{NaBH}_{4}$ in dioxane for $36 \mathrm{~h}$ or until the conversion was $100 \%$.

$b_{\text {Purified by column chromatography. }}$

${ }^{c}$ The $e e$ was determined using a Crompack Chirasil-Dex-CB GC column. 